\title{
PHYSIOLOGICAL BASIS OF LOVE - This is Our Brain on Love
}

\author{
Nagaraja Puranik. $K^{1}$, Seema Sankeshwari²,Aparna Mulgund ${ }^{3}$
}

1. Professor; Dept. of Physiology, Karnataka Institute of Medical Sciences, Hubballi, Karnataka state, India.

2. PG student, Dept. of Physiology, Karnataka Institute of Medical Sciences, Hubballi, Karnataka state, India.

3. Ist Phase MBBS student, Karnataka Institute of Medical Sciences, Hubballi, Karnataka state, India.

\begin{abstract}
Falling in love is one in all the great feeling in the world. Humans are not the only one among the huge diversity of species to fall for it. Combine bonding, the two-by-two partnering of creatures have been seen across the fauna. To fall in love and be enamoured allows an individual to depict himself charmingly alive. Most folks will reminisce at least one time in their lives of experiencing "butterflies in their stomach", or a sense of 'losing oneself' into a deep ocean of affectionate feelings for someone. We tend to encounter ourselves into being obsessional, and few might have delineated their feelings as going mad for that person. Though all these descriptions appear to be magnifying the words or phrases which we come across in daily life, there appears to have some hidden facts to these thoughts and behaviours. Have you ever thought, from where would be these sensations, obsessional thoughts and sometimes out of character acts arising from? Are there any physiological changes occurring in our body which are answerable to the arousal of these feelings? The knowledge available to biologists have advanced vastly within the previous few decades and are using that information in deciphering the Physiology involved in both combined bonding and being in love. This review could prove engrossing and to converse about the physiological basis of affection, specially metamorphology of love in various phases of life, biological basis, neurochemistry, the neuronal circuits of affection and finally concerning over the myth of 'Everlasting Love'.
\end{abstract}

KEYWORDS: Romantic love;Neurochemistry; Neurochemical; Phenylethylamine; Lasting Love

\section{INTRODUCTION}

T Whink of the last time you bumped into someone you discover endearing. You would have stuttered; your palms would have flushed, and you would have uttered something implausibly stupid and tripped stunningly while attempting to walk away. Likely your heart was 'thumping' in your chest. It's no surprise that for hundreds of years folks thought - love aroused cordially from the centre, but now it seems love is all concerned to the brain. This, in turn, makes the remainder of your body go chaotic [1].

According to a panel of researchers led by Dr H. Fischer at Rutgers, romantic love can be divided into 3 classes- lust, attraction, and attachment.
Every type is characterized by its own set of hormones stemming from the brain [2].

Romantic and maternal loves are considered to be extremely rewardable experiences. Each one connected to the continuance of the species and thus has a closely related biological perform of crucial developmental importance. The newly developed ability to check the neural correlates of subjective mental states with brain imaging techniques has allowed neurobiologists to derive to one thing precisely, i.e. concern about the neural basis of both romantic and maternal love [2]. Each form of attachment activates regions specific to every similar as well as overlapping regions in the brain's reward system, that coincide with the areas wealthy in Pitocin and 
Pitressin receptors. Each deactivates a typical set of the areas related to negative emotions, social judgement, and the assessment of the rest of the people's intentions and emotions. Thus, human attachment appears to recruit a pushpull mechanism that overcomes social distance by deactivating networks used for crucial social assessment and negative emotions, whereas it bonds people through the involvement of the reward system of the body, explaining the potentiality of love to persuade or elate oneself [3]. Yet, the biological study of deep affection, particularly romantic love, should transcend and plough for biological insights that can be extracted from the global literature of intimacy and therefore bring the humanities into its orbit.

\section{Evolutionary and biological basis of love}

From the outlook of metamorphic psychology, the incidents and behaviours linked with love may be investigated in terms of how their configuration changed bit by bit based on humans' process of evolution. To take an example, it has been advised that human language has been elated throughout the evolution process as a sort of "mating signal" that permits potential mates to evaluate productive fitness of each other. Geoffrey F. Miller portrayed that developmental psychology as a basis to go in-depth of research analytics. He delineated 'Cognitive neurobiology may try and localize romantic adaptations in the brain' [4]. But most significantly, we want far better observations regarding real-life human romantic adaptations together with the measurable aspects of romance that influence in mate selection and the generative (or a minimum of sexual) consequences of individual variation in above-mentioned aspects, along with the sociocognitive and emotional mechanisms involved in the profound affectionate phenomenon.

Since Darwin's time, there are similar speculations concerning the evolution of human interest in 'music', and music as a possible communicating medium for attracting and interpreting the worth and suitability of potential mates. It's been assumed that the human capacity to feel love has been evolved as an indication to the corresponding mate that the partner will be virtuous and possibly assisting in being one of the genes en passant to future generations. Scientist Jeremy defines love as "Unconditional selflessness", suggesting completely cooperative instincts developed in trendy humans' forbearers [5].

\section{Gratifying ourselves with love}

In 2005, H. Fischer and his research team for the crave of unveiling the mechanisms involved in the love phenomenon revealed a groundbreaking study, i.e. the primary usefulness of functional magnetic resonance imaging (fMRI) pictures of the brain of people who have fallen in love. Nearly 2500 faculty students were told to view the pictures of their special ones, and fMRI scans were obtained. The obtained brain scans were examined, analysed, and compared with the ones who viewed the footage of acquaintances. Photos of individuals, they were romantically involved caused the participant's brains to become active in regions well off with 'Dopamine', popularly known as 'feel-good' neurochemical.

Among fMRI scans, brain regions that showed activity were the 'caudate', a section related to reward detection, expectation along with the integration of sensory experiences into social behaviour and also the 'ventral tegmental region' that is related to pleasure, targeted attention and more precisely motivation to pursue and acquire [6]. The ventral tegmental space is that part of the brain which is called 'brain's reward circuit'. This circuit is considered and to be a primitive neural network which means it's developmentally old and links with the Nucleus accumbent. A few more structures that contribute to the reward circuit are Hippocampus, Prefrontal cortex, and Amygdala- which are exceptionally sensitive to behaviours that induce pleasures like sex, selective food consumptions and drug use. Jacquiline olds, associate professor of medical speciality at Boston's Massachusetts general hospital says that "areas involved in romantic love are primitive areas of the brain". Also, she mentioned that "the areas illuminate on brain scan while speaking about a dear one". These areas can be seen as illuminatory regions for a prolonged time in a few couples [7].

Once fallen in love, once we start going insane, our brain will have surged with the chemicals related to reward circuit creating a wide range of responses like- thudding hearts, wet palms, flushed cheeks, feelings of passion and nervousness. Further to gather, our bodies to subsist the 'crisis' at hand, "cortisol" hormone levels are seen to be increased throughout the initial phase of romantic love. Also, a decrease in the neurotransmitter 5HT is observed simultaneously [8]. This depleted 5HT levels can explain Richard Schwartz's statement 'neurotic behaviours' (intrusive, maddeningly preoccupying thoughts, hopes and terrors of the initial phase of love) related to infatuation [9].

\section{Neurochemistry and neural circuits of love}

Jacquiline olds mentions that there are pieces of evidence of a high release of dopamine among love-struck people, a neurochemical which keeps 'reward system ongoing'. How a euphoric condition is experienced with the use of cocaine or alcohol, likewise dopamine is said to activate "reward system of brain" which make folks to perceive love as a pleasurable experience [10].

A study conducted by the University of California and printed in 2012 in 'Science' provides solid scientific proof for this similarity. This study reported that male fruit flies that were sexually rejected drunk fourfold the maximum amount of alcohol as fruit flies that mated with the feminine fruit flies. Schwartz beautifully phrases this observation as - 'same reward centre, but a 
different route to get there'.

Pitocin and Pitressin hormones are also said to be second-hand culprits in the development of romantic love, which play a significant role in gestation, lactation, and mother-child bonding. The so-called 'love hormone' is the solely responsible element for involving the feelings of contentment, serenity and protected. The two afore-mentioned hormones released during coitus are intensified by skin to skin contact, especially Pitocin escalates the feelings of closeness and makes the partners more closely bonded and nearer to one another [11]. A long run and dedicated maintenance of relationships are said to be caused by ADH hormone. Variations in the mode of action related to the above two hormones might justify why one's affection fades as the closeness grows [12].

In addition to the positive feelings brought about by our romance, it also deactivates the neural pathway meant for negative emotions like an excess obsession, concern, and social judgement. These positive and negative feelings involve two different neuronic pathways. Positive emotion pathway is connected between the 'Nucleus accumbens and prefrontal cortex', whereas negative emotion pathway is connected between 'Nucleus accumbens and corpus amygdyloideum' [13]. Once we are deeply involved in romantic love, the neural machinery accountable for analyzing the critics outpoured by the society, including assessments of those with whom we are romantically involved shuts down. Schwartz mused and said, maybe this is the neurotic ground for the traditional belief about love which goes as - "Love is blind".

\section{Phenylethylamine is a hormone of love}

The precursor molecule for Noradrenaline and dopamine is 'Phenylethylamine' (PEA). Humans' precedent idea of "first sight love" is believed to occur because of heightened levels of PEA in the brain, which makes one experience 'sway away' feel subjected to those involved in romantic love. Release in massive levels. The PEA increases each physical and emotional contents at once and simultaneously unleash of dopamine surge [14].

More than a half dozen of hormones and neurochemicals which are held responsible for the expertise of 'love feeling'. PEA always withholds the centre of attraction. As a result of its far fame of being found in chocolates, PEA grabs special attention [15]. Just think of times when you felt yummy, elated, and joyous after consuming your favourite chocolates. Formerly it was believed that PEA was solely meant for inducing these sensations, but now it's clear that dopamine is the one, provoking the 'feels' associated with consumption of chocolate. PEA consumed is degraded by various enzymes of GI tract, preventing it from attaining peak levels in the brain. Hence, once we eat chocolate; we tend to feel 'yummy' from the sweet taste and not by the PEA concentration present in it. In fact, cheese and sausages are the ones where you can find a high level of PEA. However, that does not seem to be related to the chemistry of affection as per the knowledge, by now. PEA's major role play is more of a neuromodulator instead as a neurochemical, compared to the afore-mentioned two [16].

Dopamine, while increasing in blood in its path, it conjointly modulates noradrenergic transmission (i.e. ignition of the noradrenergic system). In other words, it would be good to mention that PEA is kind of a 'helper' for the action of the previous two players. This mechanism of PEA is not much precise, but mostly it's assumed that whenever its level is raised in the brain, it is captured into presynaptic vesicles and occupies the place previously occupied by dopamine. This process helps in heightening the levels of dopamine extracellularly and enhances its dopaminergic transmission [17].

Thus, we can now say it's because of the chemistry of these three chemicals we tend to feel the actual "chemistry" of love. Thanks to this mixture that new lovers feel euphoriant and energized and can be pointed at for long talks of the couples all along the days and nights. However, PEA is documented to exhibit severe diurnal highs and lows property in some individuals making an 'up-down' experience of pleasure, interest, arousal, and obsession.

\section{Lasting love}

Schwartz says - if love lasts, this roller coaster of emotions starts tapering down with following few years. "The passion continues, to be there, however, the strain of it will be gone", he added. 5HT and cortisol levels come back to baseline. LOVE! That began as an agent of stress (to our brains and bodies at least), becomes a buffer against stress. Regions of the brain related to reward and pleasure are still kept in an activated state as caring relationships proceed. However, crave of constant desire and want, which is imminent with romantic love, hampers gradually [18]. Olds and Schwartz say- 'many proposed theories of love mention that there are unavoidable changes over a period of time from intense love to empathetic love, a love that's deep however not as elated as that of the love felt during initial days of romance'. That doesn't, however, mean that the spark of romance is quenched for long-married couples.

The Stony Brook University of New York in 2011 conducted a study which stated that it's possible to be deeply drowned in love with somebody for even years together, after the wedding. After conducting MRI scans on couples who had been married with a mean of twenty years, Fischer and his analysis team found a constant intensity of activity in dopamine affluent areas of the brain as found within the brains of newly 'IN LOVE' 
people. This study prompted that the thrill of romance will stay, whereas the apprehension is lost. A progressive physiological investigation on love has confirmed that when individuals say even after 20-30 years, they are 'madly in love' with their partners; are not bluffing, but it's true [19]. For those, whose long-run wedding has transitioned from intense romantic love to a lot of compassionate, i.e. a routine sort of love is a gift of dopamine action.

Olds says that it is possible to revive the blaze that characterised the relationship's initial days'we call it the rustiness development' [20]. "In later phases of life, couples get out of the habit of sexual act, of being intensely involved probably for valid reasons" - she added. However, that sort of love is often reignited. Sexual issues, as an example, will increase the Pitocin levels, which activates the brain's reward circuit, making couples more affectionate or drawn towards each other, and thus proves the evergreen quote of existing humanity- "TRUE LOVE LASTS FOREVER...."

\section{Conclusion}

Nearly 400 years after William Shakespeare asked, "What is love?", brain imaging studies are allowing scientists to give at least a partial conclusive answer that love is associated with brain and not the heart. Around 2500 years ago, Hippocrates was absolutely right in saying, "Emotions emanate from the brain". Love comes from the brain and manifest itself in the heart. As our calendar gets closer to February 14, Valentine's Day, our love and emotions will be at it's peak. Let's be modern with our understanding of love and say that, 'I love you from the centre of my brain' instead of saying,' I love you from the bottom of my heart'.

Acknowledgements: The authors gratefully acknowledge Dr. Kammar KF, Professor and Head, Department of Physiology KIMS, Hubballi for the suggestions and help given by him to prepare this review article.

\section{Source of Support: Nil}

\section{Conflict of Interest: None Declared}

\section{REFERENCES}

1. Zeki S. The neurobiology of love. FEBS Lett 2007; 581(14): 2575-79

2. Aron A, Fisher HE, Mashek, DJ, Strong G, Li HF, Brown LL. Reward, motivation, and emotion systems associated with early-stage intense romantic love: an MRI study. Journal of Neurophysiology 2005; 94: 327-37

3. Fisher HE, Aron A, Brown LL. Romantic love: A mammalian brain system for mate choice. Philos Trans R Soc Lond B Biol Sci 2006; 361(1476): 2173-86.

4. Geoffrey F Miller. The mating mind: How sexual choice shaped the evolution of human nature archived? Psychology 2001; 12: 8 .
5. Griffith, Jeremy. Beyond the Human Condition. In WTM Publishing \& communications Ltd 1991: 203.

6. Fisher H, Aron A, Brown LL. Romantic love: an fMRI study of a neural mechanism for mate choice. J Comp Neurol 2005; 493(1): 58-62.

7. Edward Kravitz. Love and the brain. In Harvard Mahoney Neuroscience Institute, On the Brain Newsletter and the Brain Series 1992.

8. Marazziti D, Akiskal HS, Rossi A, Cassano, GB. Alteration of the platelet serotonin transporter in romantic love. Psychol Med 1999; 29(3):741-5.

9. Edwards and Scott. Love and the brain. Harvard mahoney neuroscience Institute 2010. In neuro. hms.harvard.edu.

10. Tabitha MP. Addiction and the brain: The dopamine pathway is helping researchers find their way through the addiction maze. Bio Science 1999; 49(7): 513-9.

11. Navneet, Magon and Sanjay, Kalra. The orgasmic history of oxytocin: Love, lust, and labor. Indian J Endocrinol Metab 2011; 15(Suppl3): S156-61.

12. Young LJ. Oxytocin and vasopressin receptors and species-typical social behaviors. Hormones and Behavior 1999; 36: 212-21.

13. Damasio AR, Grabowski TJ, Bechara A, Damasio H, Ponto, LL., Parvizi. Sub cortical and cortical brain activity during the feeling of self-generated emotions. Nat neurosci 2000; 3: 1049-56.

14. Parker EM, Cubeddu LX. Comparative effects of amphetamine, phenylethylamine and related drugs on dopamine efflux, dopamine uptake and mazindol binding. Journal of Pharmacology and Experimental Therapeutics 1988; 245(1): 199.

15. Koehl PE, Eienmiller RR. High pressure liquid chromatographic analysis of tyramine, phenylethylamine and tryptamine in sausage, cheese and chocolate. Journal of food science 1978; 43(4):1245.

16. Szabo A, Billett E, Turner, J. Phenylethylamine, a possible link to the antidepressant effects of exercise? Br. J. Sports Med 2001; 35(5): 342-3.

17. Takefumi, Miyazaki and Michael, G Lacey. Pre synaptic inhibition by dopamine of a discrete component of GABA release in rat substantia nigra pars reticulata. J Physiol. 1998;15 (513): 805-17.

18. Brian D Earp, Olga A., Wudarczyk, Anders Sandberg and Julian Savulescu. If I could just stop loving you: Anti-Love Biotechnology and the Ethics of a Chemical Breakup. Am J Bioeth 2013; 13(11): 3-17.

19. Fisher HE, Xiaomeng $\mathrm{Xu}$, Aron A, Lucy L. Brown. Intense, passionate, romantic love: a natural addiction? How the fields that investigate romance and substance abuse can inform each other. Front Psychol 2016; 7: 687.

20. Cho MM, De Vries AC, Williams JR, Carter CS. The effects of oxytocin and vasopressin on partner preferences in male and female prairie voles (microtusochrogaster). Behavioral Neuroscience 1999;113(5):1071-9. 